Available online on 15.08 .2020 at http://jddtonline.info
Open Access to Pharmaceutical and Medical Research
unrestricted non-commercial use, provided the original work is properly cited

Open 1 Access

Research Article

\title{
Does BMI Really Alter the Hormonal Profile in Infertile Women? Retrospective Study in the Region of Sidi Bel Abbes (West Algeria)
}

\author{
Khalloua Zine Charaf;, Chebli I., Meziani S.; Ferrag D., Itatahine A., MAÏ H., Bekhadda H., Benali A., Bensaid I., \\ Demmouche A.*, Belbraouet S. $^{2}$
}

${ }^{1}$ Biotoxicology laboratory, Department of Biology, Faculty of Natural Sciences and life-Djillali Liabes University of Sidi Bel Abbes, Algeria

2 University of Moncton, School of Nutrition, Moncton, Nouveau-Brunswick, CANADA

\begin{abstract}
Background: In last few years .; it's increasingly being recognized that Reproductive function is controlled by the hypothalamic-pituitarygonadal axis, which is regulated by numerous endogenous and environmental factors such us adipose accumulation in obesity contributing to reproductive failure such as menstrual disorders and infertility, gestational failure and obstetric complications, and infer tility, Distinct changes in circulating sex hormones appear to underline these abnormalities.

The objective: The aim of this study was to elucidate the possible correlation between body mass index as fatness indicator and hormonal profile in infertile women from the west of Algeria. To identify the impact of overweight and obesity on female hormonal profile ; we conducted a prospective study measuring pituitary hormones (FSH and LH and prolactin ), steroid sex hormones ( progesterone , testosterone and estradiol ), anti miulleian hormone, and thyroidal hormones (FT3, FT4 and TSH) in 360 women consulting for subfertility in private genecologycal and obstetrical centers in SIDI BEL ABBES (West of Algeria)

Result: Our study showed that the majority of patients were aged between 20 and 29 years, representing a percentage of $47.8 \%$, with the average age in sample (31.65 $\pm 6,93 \mathrm{ans})$. The majority of subjects was obese $46.4 \%$, or overweight (39.4\%) with an average BMI of (29.76 \pm $4,85 \mathrm{Kg} / \mathrm{m} 2$ ). No statistically significant association was found between the BMI as obesity indicator with hormonal levels of pituitary hormones (FSH and LH and prolactin ), steroid sex hormones (progesterone, testosterone and estradiol ), anti miulleian hormone, and thyroidal hormones (FT3 , FT4 and TSH). A negative and statistically significant correlation between the age of the patients and the AMH level $(\mathrm{R}=-0.60, \mathrm{P}<0.01)$ was noted.
\end{abstract}

Conclusion: The results of our study showed that the majority of women included in our study had a high BMI but no statistical significant difference was found between underweight, normal, overweight and obese women, that's why more studies should be conducted to elucidate the level in which does obesity impair the reproductive outcomes

Keywords: Female infertility, hormonal profile, BMI, SBA, Algeria.

Article Info: Received 13 June 2020; Review Completed 26 July 2020; $\quad$ Accepted 05 August 2020; Available online 15 August 2020

Cite this article as:

Khalloua ZC, Chebli I, Meziani S, Ferrag D, Itatahine A, MAÏ H, Bekhadda H, Benali A, Bensaid I, Demmouche A,

Belbraouet S, Does BMI Really Alter the Hormonal Profile in Infertile Women? Retrospective Study in the Region of Sidi

Bel Abbes (West Algeria), Journal of Drug Delivery and Therapeutics. 2020; 10(4-s):142-147

http://dx.doi.org/10.22270/jddt.v10i4-s.4320

*Address for Correspondence:

DEMMOUCHE A., Biotoxicology laboratory, Department of Biology, Faculty of Natural Sciences and life-Djillali Liabes University of Sidi Bel Abbes, Algeria

\section{INTRODUCTION}

The physiological and behavioural aspects of reproductive abnormalities are in part caused by unbalanced nutrition and corporal reserve that refers to obesity which is defined by the World Health Organization (WHO) as "abnormal or excessive fat accumulation that may impair health 1,2 . In Algeria the prevalence of obesity and overweight are respectively $9 \%$ and $27 \%$ for men and $21 \%$ and $53.5 \%$ for women ${ }^{1}$. The body mass index (BMI) is the metric currently in use for defining anthropometric characteristics in adults

ISSN: 2250-1177 and for classifying (categorizing) them into groups. Specifically, BMI is a ratio of an individual's weight in kilograms divided by his height squared in meters. The WHO has set forth standards to classify individuals as underweight, normal, overweight or obese. In particular, a BMI of $18.5-24.99 \mathrm{~kg} / \mathrm{m} 2$ is classified as normal, 25-29.99 $\mathrm{kg} / \mathrm{m} 2$ as overweight, $30-34.99 \mathrm{~kg} / \mathrm{m} 2$ as class I obesity, $35-$ $39.99 \mathrm{~kg} / \mathrm{m} 2$ as sever obesity [1, 3].. The common interpretation of BMI is that it represents an index of an individual's fatness. It also is widely used as a risk factor for 
the development of or the prevalence of several health issues caused by obesity such as cardiovascular disease, diabetes, osteoarthritis and malignancies 1 . It is increasingly being recognized that this current obesity epidemic has also contributed to reproductive failure such as menstrual disorders and infertility, gestational failure and obstetric complications, and infertility ${ }^{1-3}$, wich is defined as defined as the failure to conceive a recognized pregnancy after 12 months of unprotected intercourse, carries 4, 5 . Distinct changes in circulating sex hormones appear to underline these abnormalities. Because Reproductive function is controlled by the hypothalamic-pituitarygonadal axis, which is regulated by numerous endogenous and environmental factors such us adipose accumulation in obesity. In Algeria and developing countries in general a very limited number of studies have been conducted on the impact of body mass index (BMI) on female infertility ${ }^{6}$.

The present study aims to elucidate the possible correlation between body mass index as corpulence indicator and hormonal profile in infertile women from the west of Algeria.

\section{SUBJECTS AND METHODS:}

This prospective, comparative study was conducted in period January-April 2018 and it included a total of 360 women consulting for infertility in different medical centres of genecology and obstetrics in Sidi Bel Abes in western Algeria. Subjects were divided into four groups according to their corpulence (underweight, normal overweight and obese). After measuring their height and weight.

\section{Sampling}

Blood sampling was performed in the early follicular phase (between days 2 and 5 after the last menstrual period) on fasting by venipuncture. The blood was allowed to clot, then serum was collected for analysis. The following hormonal analyses were performed in all subjects: follicle-stimulating hormone (FSH), luteinizing hormone (LH), estradiol (E2), total testosterone (TT), prolactin (PRL), Anti miullerien hormone AMH, T3 and T4.

Serum concentration of Leutinizing Hormone (LH), Follicle s timulating hormone (FSH) and Prolactin (PRL) ; estradiol (E2), total testosterone (TT), prolactin (PRL), Anti miullerien hormone AMH, T3 and T4 were measured by the microwell enzyme linked immunosorbent assay (ELISA) technique bas ed on the non competitive sandwich principle, while Progest erone and Estradiol were measured based on competitive EL ISA principle (test)

\section{Statistical analysis}

For statistical analysis, data were entered and analyzed by the SPSS (22 version). Frequencies and the percentages were calculated and Student's $t$ test was performed to investigate the significance in the association of the BMI and infertility. Correlations were considered significant if the observed significance level $\mathrm{p}$ was $<0.05$. Chisquare test was used as test of significance at $5 \%$ level.

\section{RESULTS:}

\section{Age of patients}

The majority of patients were aged between 20 and 29 years, representing a percentage of $47.8 \%$, with the average age in sample (31.65 $\pm 6,93 \mathrm{ans})$. For the age groups of 30 to 39 and over 40 years they represented respectively (34.4\% and $14.7 \%$ ). The smaller number of cases was found in younger women $<20$ years with a percentage of (3.1\%).(table 1).

\section{Distribution of patients according to the type of infertility}

The majority of subject had a primary infertility $(84.2 \%)$ whereas secondary infertility represented $(15,8 \%)$ of subjects .

\section{Distribution of patients according to their BMI}

The study revealed that $(39.4 \%)$ of the patients (142 cases) had a BMI between $25-29.9 \mathrm{Kg} / \mathrm{m} 2$ which is considered as overweight ; for obesity a BMI> $30 \mathrm{Kg} / \mathrm{m} 2$ there were 167 cases(46.4\%), the average BMI was $\left(29.76 \pm 4,85 \mathrm{Kg} / \mathrm{m}^{2}\right)$.

\section{Distribution of patients depending to the hormonal profile}

The study of the hormonal profile of patients reveals that the majority of women with infertility had normal levels of hormones $(70 \%$ to $90 \%)$, some patients had reduced levels of AMH (60\%) FT3 (34.4\%) FT4 (26.6\%). The percentage of reduced level for other hormones is between $10 \%$ and $6.9 \%)$.

While hormones identified with higher level our patients are prolactin $(42.8 \%)$ testosterone $(34.3 \%)$ and between $(2.2 \%$ and 18.6\%), for the other hormones (Table 1).

The relationship between the various hormones and BMI studied patients is described in Table 2 .

A significant relationship between these two parameters were noted only in the FSH level $(P=0.022)$, the much higher levels $(9,4 \pm 6,12 \mathrm{mIU} / \mathrm{ml})$ were found in patients in the age group 21 to 30 years (Table 1 ).

For other hormones studied, there was no significant relationship between patient age and hormonal level, against all hormones analyzed the results show that abnormal levels are found in older patients than with normal levels, and levels increase in proportion with age (Table 1).

\section{BMI and hormonal profiles}

The relationship between the various hormones and BMI studied patients is described in Table 2

\section{BMI and Gonadostimulating hormones}

The serum levels of gonadostimulating hormones FSH and LH didn't show any statistical significance between the four groups the $\mathrm{P}=0.5$ for $\mathrm{FSH}$ and 0.54 for $\mathrm{LH}$, even if we observed a higher LH average level in in underweight group. So no negative correlation could be established between BMI and gonaodostimulating hormones in our study.

\section{BMI and steroid hormones:}

in the underweight group The average level of oestrogen was seven times lower than other groups, beside the testosterone showed also a lower concentration in this group comparing to the three other groups that had nearly the same concentration of this hormone, however the concentration of progesterone was higher in underweight group compared to the normal corpulence group that showed the lowest level of progesterone with a concentration of $9,61 \pm 9,8 \mathrm{ng} / \mathrm{mL}$. The statistical analysis of this result did not show any statistical significance with $\mathrm{P}>0.05$

\section{BMI and AMH}

The anti-Müllérian hormone was not measured in underweight patients, the level of this hormone showed a proportional increase of the concentration with the higher 
BMI groups but with no statistical significance $(R=-0.136, P$ $=0.578)$, (figure 1 ).

\section{BMI and thyroidal profile}

The TSH level was nearby the same in the four groups with no statistical difference. Beside the FT3 and the FT4 was not dosed in the underweight women, and there concentration was the same practically in all groups .

\section{Age and hormonal profile}

The relationship between the different hormones studied and the age of the patients is described in (Table 3). A significant relationship was noted for the AMH rate between these two parameters $(\mathrm{P}=0.026)$, AMH levels decrease with increasing patient age, the difference between the two age categories extreme $(<20$ and $>40)$ was very high with mean AMH levels respectively of (36.86 $\pm 8.27 \mathrm{pmol} / \mathrm{l}$ and $3.34 \pm 2.21 \mathrm{pmol} / \mathrm{l}$ ), (Table 3).

A negative and statistically significant correlation between the age of the patients and the AMH levels $(\mathrm{R}=-0.60, \mathrm{P}$
$<0.01$ ), reduced AMH levels are thus found in the oldest patients (Figure 2).

\section{Hormone level and type of infertility}

Table 2 shows the comparison of hormonal profile with infertility. Women with secondary infertility had significantly higher $(\mathrm{P}<0.05) \mathrm{FSH}, \mathrm{LH}, \mathrm{TSH}, \mathrm{T} 3$, T4, progesterone and estradiol than women with primary infertility. There was no significant difference $(P>0.05)$ in the $\mathrm{LH}$ level of the nonmenstruating and menstruating infertile women

FSH values were highest $(10,15 \pm 3,12 \mathrm{mIU} / \mathrm{ml})$ in primary and lowest $(6,61 \pm 2,3.33 \mathrm{mIU} / \mathrm{ml})$ in secondary group.

LH levels for primary infertile group were the highest $(8,33 \pm 7,71 \mathrm{IU} / \mathrm{L})$ while secondary infertile group had the lowest mean concentration $(7,69 \pm 5,09 \mathrm{IU} / \mathrm{L})$. There was no significant difference $(\mathrm{P}=0.82)$.

The levels of OESTRADIOL for primary were higher $(73,54 \pm 58,74 \mathrm{pg} / \mathrm{ml})$ than the secondary $(48,32 \pm 22,09$ $\mathrm{pg} / \mathrm{ml}$ ), (Table 4.)

Table 1 : distribution of patients according to their hormonal levels

\begin{tabular}{|l|l|l|l|l|l|l|}
\hline Hormones & N & $\begin{array}{l}\text { Average } \begin{array}{l}\text { Intandard } \\
\text { deviation }\end{array} \\
\text { FSH (mIU/ml) }\end{array}$ & $\begin{array}{l}\text { Reduced } \\
\text { level }\end{array}$ & Normal level & Increased level & Baseline \\
LH(IU/L) & 360 & $8,54 \pm 5.4$ & $70(19.4 \%)$ & $272(75.6 \%)$ & $18(5 \%)$ & $4,7-21,5 \mathrm{mIU} / \mathrm{ml}$ \\
Progesterone(ng/mL) & 360 & $8,40 \pm 5,7$ & $25(6.9 \%)$ & $268(74.4 \%)$ & $67(18.6 \%)$ & $2,4-12,5 \mathrm{IU} / \mathrm{L}$ \\
Prolactin(ng/ml) & 360 & $25,6 \pm 19,1$ & $74(20.6 \%)$ & $261(72.5 \%)$ & $25(6.9 \%)$ & $2-25 \mathrm{ng} / \mathrm{mL}$ \\
TSH( $\boldsymbol{n U} / \mathbf{m L})$ & 360 & $3,2 \pm 2,4$ & $6(1.7 \%)$ & $200(55.6 \%)$ & $154(42.8 \%)$ & $4-23 \mathrm{ng} / \mathrm{ml}$ \\
Estradiol (pg/mL) & 360 & $51,3 \pm 47,7$ & $21(5.8 \%)$ & $235(65.3 \%)$ & $104(28.9 \%)$ & $0,4-4,2 \mu \mathrm{U} / \mathrm{mL}$ \\
AMH (pmol/l) & 5 & $18,9 \pm 18,3$ & $3(19.2 \%)$ & $283(78.6 \%)$ & $8(2.2 \%)$ & $12-166 \mathrm{pg} / \mathrm{mL}$ \\
Testosterone (ng/ml) & 35 & $2,09 \pm 3,3$ & $0(0 \%)$ & $23(65.7 \%)$ & $(34.3 \%)$ & $21-40 \mathrm{pmol} / 1$ \\
FT3 (pg/mL) & 122 & $2,9 \pm 1,1$ & $42(34.4 \%)$ & $68(55.7 \%)$ & $12(9.8 \%)$ & $2,30-4,20 \mathrm{pg} / \mathrm{mL}$ \\
FT4 (ng/dL) & 124 & $1,4 \pm 1,2$ & $33(26.6 \%)$ & $63(17.5 \%)$ & $28(22.6 \%)$ & $1-1,60 \mathrm{ng} / \mathrm{Dl}$ \\
\hline
\end{tabular}

Table 2: Distribution of patients according to hormonal profiles and BMI

\begin{tabular}{|c|c|c|c|c|c|}
\hline BMI & $<=18,5$ & $18,5-24,9$ & $25-30$ & $>30$ & $\mathbf{P}$ \\
\hline FSH & $7,08 \pm 0,4$ & $9,0 \pm 5,5$ & $8,92 \pm 5,69$ & $8,10 \pm 5,12$ & 0,50 \\
\hline LH & $14,0 \pm 4,6$ & $8,30 \pm 5,04$ & $8,35 \pm 5,42$ & $8,40 \pm 5,53$ & 0,54 \\
\hline Progesterone & $19,9 \pm 5,06$ & $9,61 \pm 9,8$ & $11,87 \pm 8,96$ & $11,33 \pm 8,91$ & 0,25 \\
\hline Prolactine & $14,21 \pm 4,64$ & $24,44 \pm 8,15$ & $24,05 \pm 8,97$ & $27,50 \pm 9,50$ & 0,32 \\
\hline TSH & $3,40 \pm 3,08$ & $2,80 \pm 2,17$ & $3,33 \pm 2,54$ & $3,23 \pm 2,64$ & 0,64 \\
\hline OEstradiol & $8,50 \pm 1,60$ & $51,03 \pm 4,92$ & $55,37 \pm 4,04$ & $48,63 \pm 4,04$ & 0,36 \\
\hline AMH & & $10,78 \pm 8,25$ & $24,04 \pm$ & $37,25 \pm 3,78$ & 0,26 \\
\hline Testosterone & 0,75 & $2,47 \pm 1,21$ & $2,17 \pm 1,91$ & $1,98 \pm 1,16$ & 0,67 \\
\hline FT3 & & $3,33 \pm 0,82$ & $3,03 \pm 1,27$ & $2,88 \pm 1,11$ & 0,47 \\
\hline FT4 & & $1,23 \pm 0,26$ & $1,42 \pm 1,11$ & $1,56 \pm 1,47$ & 0,67 \\
\hline
\end{tabular}


Table 3: distribution of patients according to the relationship between their hormonal profile and age

\begin{tabular}{|c|c|c|}
\hline Age of patients & Average \pm standard deviation & $\mathbf{P}$ \\
\hline & FSH(mIU/ml) & \\
\hline $21-30$ & $5,69 \pm 1,90$ & 0.083 \\
\hline $31-40$ & $6,54 \pm 2,60$ & \\
\hline \multirow[t]{2}{*}{$>40$} & $15,24 \pm 8,83$ & \\
\hline & LH(IU/L) & \\
\hline $21-30$ & $8.13 \pm 6,12$ & 0.659 \\
\hline $31-40$ & $8,05 \pm 4,17$ & \\
\hline \multirow[t]{2}{*}{$>40$} & $8,81 \pm 1,19$ & \\
\hline & Prolactine (ng/ml) & \\
\hline $21-30$ & $19,57 \pm 9,94$ & 0.550 \\
\hline $31-40$ & $34,58 \pm 8,37$ & \\
\hline \multirow[t]{2}{*}{$>40$} & $27,22 \pm 3,02$ & \\
\hline & Estradiol (pg/ml) & \\
\hline $21-30$ & $56,38 \pm 6,52$ & 0.384 \\
\hline $31-40$ & $48,40 \pm 5,03$ & \\
\hline \multirow[t]{2}{*}{$>40$} & $88,67 \pm 7,68$ & \\
\hline & $\operatorname{TSH}(\mu \mathrm{U} / \mathrm{mL})$ & \\
\hline $21-30$ & $3,31 \pm 2,41$ & 0.691 \\
\hline $31-40$ & $2,57 \pm 1,49$ & \\
\hline \multirow[t]{2}{*}{$>40$} & $2,56 \pm 2,27$ & \\
\hline & AMH(pmol/l) & \\
\hline$<=20$ & $36,86 \pm 8,27$ & $0,026^{*}$ \\
\hline $21-30$ & $27,91 \pm 2,43$ & \\
\hline $31-40$ & $22,14 \pm 6.79$ & \\
\hline \multirow[t]{2}{*}{$>40$} & $3,34 \pm 2,21$ & \\
\hline & FT4(ng/dL) & \\
\hline $21-30$ & $12,01 \pm 6,33$ & 0,695 \\
\hline $31-40$ & $9,16 \pm 7,53$ & \\
\hline \multirow[t]{2}{*}{$>40$} & $7,25 \pm 8,56$ & \\
\hline & FT3(pg/mL) & \\
\hline $21-30$ & $2,32 \pm 2,05$ & 0,730 \\
\hline $31-40$ & $3,20 \pm 1,56$ & \\
\hline$>40$ & $2,66 \pm 1,72$ & \\
\hline
\end{tabular}

*: significant $\mathbf{P}<\mathbf{0 . 0 5}$

Table 4: Distribution of patients according to hormone level and type of infertility

\begin{tabular}{llll}
\hline \multirow{2}{*}{ Hormone } & \multicolumn{2}{c}{ Type of infertility } & P \\
\cline { 2 - 4 } & Primairy & Secondary & \\
\hline FSH $(\mathrm{m} I U / \mathrm{ml})$ & $10,15 \pm 3,12$ & $6,61 \pm 2,3.33$ &, 432 \\
\hline LH$(\mathrm{IU} / \mathrm{L})$ & $8,33 \pm 7,71$ & $7,69 \pm 5,09$ &, 821 \\
\hline Estradiol $(\mathrm{pg} / \mathrm{ml})$ & $73,54 \pm 58,74$ & $48,32 \pm 22,09$ &, 377 \\
\hline Prolactine $(\mathrm{ng} / \mathrm{ml})$ & $26,78 \pm 21,49$ & $36,39 \pm 70,53$ &, 494 \\
\hline TSH $(\mu \mathrm{U} / \mathrm{mL})$ & $2,89 \pm 2,36$ & $2,34 \pm 1,26$ &, 515 \\
\hline T3 $(\mathrm{pg} / \mathrm{mL})$ & $3,33 \pm 1,66$ & $1,84 \pm 1,27$ &, 108 \\
\hline T4 $(\mathrm{ng} / \mathrm{dL})$ & $11,58 \pm 6,15$ & $5,39 \pm 7,44$ &, 180 \\
\hline AMH $(\mathrm{pmol} / \mathrm{l})$ & $11,18 \pm 15,91$ & $22,58 \pm 39,31$ &, 325 \\
\hline
\end{tabular}




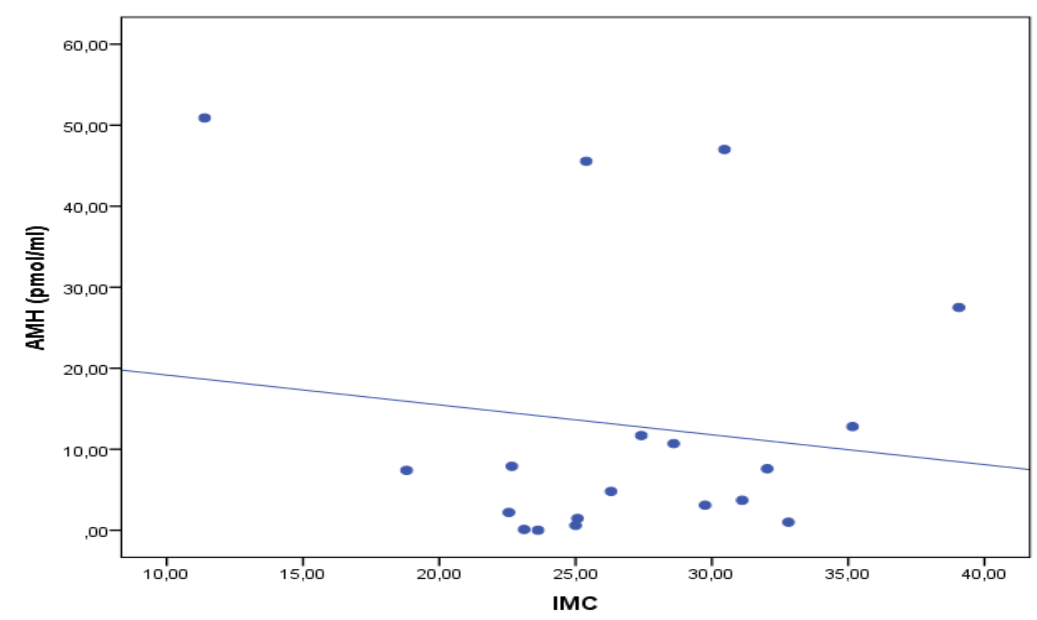

Figure 1 : Correlation between BMI of patients and AMH LEVEL

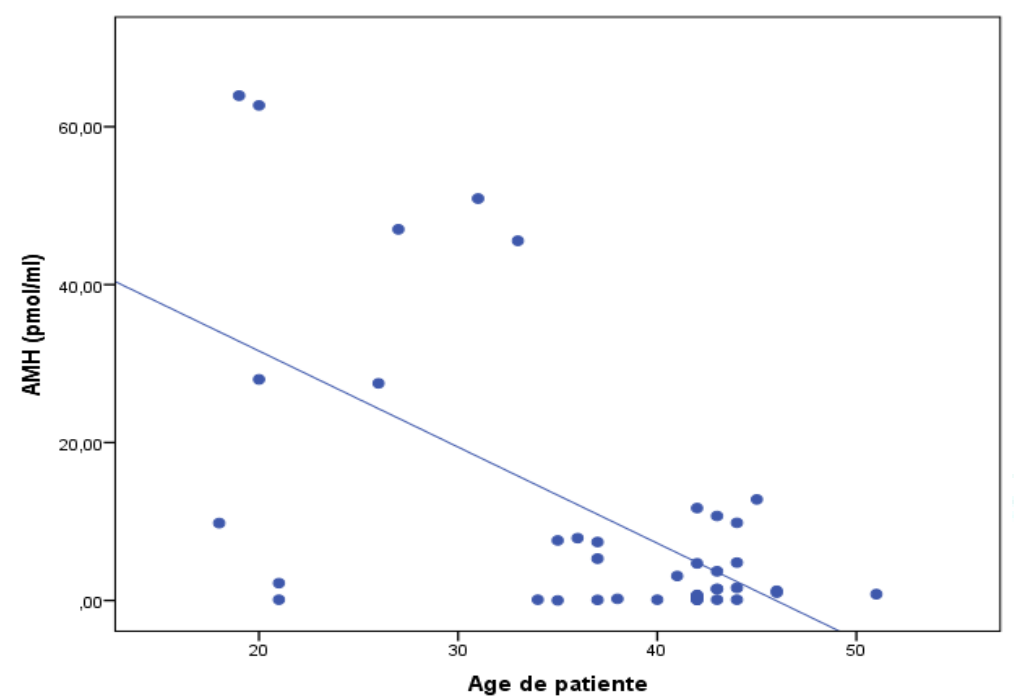

Figure 2 : Correlation between age of patients and AMH LEVEL

\section{DISCUSSION:}

Infertility affects approximately one in six couples during their lifetime. Obesity affects approximately half of the general population and is thus a common problem among the fertile population. The prevalence of obesity in infertile women is high, and it is well known that there is an association between obesity and infertility. Obesity also has a profound impact on reproductive health. Women who have obesity are at increased risk for menstrual dysfunction, anovulatory infertility and pregnancyrelated complications.

Several epidemiological and observational studies provide evidence for the relationships between obesity and reproductive pathologies, ranging from early in the onset of puberty to menopause but only few of them focuses on the place of the impact of endocrinal disturbance caused by obesity and especially hypothalamic-pituitary- gonadal axis which control hormonal profiles in overweight and obese subfertile women 7,8 .

The present study revealed that The majority of patients were aged between 20 and 29 years, representing a percentage of $47.8 \%$, with the average age in sample $(31.65$ \pm 6,93ans). That's may be a explained local sociodemographic factors.

The majority of women consulting for subfertility was obese or overweight this result concord with those found by
Boudia et al., 2015; Isa AM, 2014 and Filer, 2009 8,9,10. These statistics are very disturbing from a public health point of view as this group of patients is a random sample of Algerian women as the obesity is considered as a sanitary psycho-soscio-economical problem that not only alters the individual well-being but also exhaust the budget conserved to healthcare and social security.

No statistically significant association was found between the BMI as obesity indicator with hormonal levels of pituitary hormones (FSH and LH and prolactin), steroid sex hormones ( progesterone, testosterone and estradiol ) , anti miulleian hormone, and thyroidal hormones (FT3, FT4 and $\mathrm{TSH}$ ), this results are in agreement with those found by Roth et al ., 201411.

However, this remains controversial for some authors, who showed that overweight and obese infertile women had lower basal serum FSH, LH and estradiol levels than normal weight women ${ }^{12,13}$. Other studies that suggested that high level of androgen have a tight concomitant correlation with the visceral adiposity known as android fats accumulation in women 14. Other investigations showed higher oestrogen amounts in obese women what could be explained by the fact that in premenopausal women, cyclical changes in plasma estrogen levels result from a complex set of stimuli, including feedback controls on ovarian steroidogenesis and follicular development mediated by LH and FSH, Estrogen synthesis 
in subcutaneous fat also occurs in premenopausal women 15 . Generally, this contributes on average about $5 \%$ of the total plasma estradiol synthesis across the menstrual cycle but in cases of extreme obesity the markedly increased levels of estrogen released into the circulation from the adipose tissue activates the negative feedback in the hypothalamus pituitary axis leading to reduced gonadotrophin secretion. In such extreme cases, this can lead to a complete switch off of normal ovarian function and be reflected in amenorrhea 16,17 .

This controversial results in different studies would be due to A potential weakness is that the study designs and methods for measuring hormones and other risk factors were not standardized. For example, studies variably used forward or backward dating in determining when blood was collected in the menstrual cycle, and, because of differences in progesterone measurement across study, we were unable to distinguish ovulatory versus anovulatory cycles. Further, hormone concentrations varied substantially between studies. Some of this variation in mean hormone concentrations between studies is due to differences in the timing of sample collection, for example the relatively low mean oestradiol concentrations in the follicular phase in some studies where samples were collected on days 3-5 of the cycle, and the relatively high mean luteal phase progesterone concentrations samples collected in the middle of the luteal phase in other studies 18, 19. Some of the variation between studies is likely to reflect differences in assay methods. The accuracy of assay methods varies, and assays which incorporate an extraction step are more accurate than "direct" non-extraction assays 20,21. Further research is needed to determine the environmental and genetic factors that cause differences in hormone levels among premenopausal overweight and obese women.

\section{CONCLUSION:}

The results of our study shows that the majority of the subfertile women were young with a high BMI $(<25$ years $)$ this fact enhance the estimated negative impact of overweight and obesity on reproductive function even if our result did't show any significant difference in hormonal levels in underweight, normal, overweight and obese women. That why further researches are needed to elucidate the mechanism involved in the impaired reproductive function in obese and overweight premenopausal women. Weight loss has beneficial effects on the reproductive outcomes in these patients.

\section{Competing of interest}

Authors declared that they have no competing of interest.

\section{REFERENCES:}

1. Khullar, K., Agarwal, A., \& Du Plessis, S. S. A hormonal, physical, and proteomic view of obesity-induced effects on male infertility and possible lifestyle modifications. Asian Pacific Journal of Reproduction. 2012; 1:161-168.

2. Nuttall, F. Q. Body mass index: obesity, BMI, and health: a critical review. Nutrition today. 2015; 3:117.
3. Pandey, S., Maheshwari, A., \& Bhattacharya, S. The impact of female obesity on the outcome of fertility treatment. Journal of human reproductive sciences. 2010; 2:62.

4. Campos, D. B., Palin, M. F., Bordignon, V., \& Murphy, B. D. The'beneficial'adipokines in reproduction and fertility. International Journal of Obesity. 2008; 2:223.

5. Norman, J. E. The adverse effects of obesity on reproduction. Reproduction. 2010; 140:343-5.

6. Norman JE, The adverse effects of obesity on reproduction, Reproduction, 2010; 140(3):343-345. doi: 10.1530/REP-100297

7. Ruder, E. H., Hartman, T. J., Blumberg, J., \& Goldman, M. B. Oxidative stress and antioxidants: exposure and impact on female fertility. Human reproduction update . 2008; 14:345-357.

8. Isa AM, Abu-Rafea B, Alasiri SA, Binsaleh S, Ismail KH, Vilos GA Age, body mass index, and number of previous trials: are they prognosticators of intra-uterine-insemination for infertility treatment?. International Journal of Fertility \& Sterility. 2014; $8(3): 255-260$

9. FERIEL BOUDIA, ABBASSIA DEMMOUCHE AND HICHAM ABDESSALEM MAÏ. THE IMPACT OF FEMALE BODY WEIGHT ON INFERTILITY. Journal of Disease and Global Health. . 2015; 3:3438

10. Filer, B. R. Obesity and reproduction. JLGH. . 2009; 4(4):134135.

11. Roth, L. W., Allshouse, A. A., Bradshaw-Pierce, E. L., Lesh, J., Chosich, J., Kohrt, W., ... \& Santoro, N. Luteal phase dynamics of follicle-stimulating and luteinizing hormones in obese and normal weight women. Clinical endocrinology. 2014; 81(3):418425.

12. Pasquali, R., Pelusi, C., Genghini, S., Cacciari, M., \& Gambineri, A. Obesity and reproductive disorders in women. Human reproduction update. 2003; 9(4):359-372.

13. Crujeiras, A. B., \& Casanueva, F. F. Obesity and the reproductive system disorders: epigenetics as a potential bridge. Human reproduction update. . 2014; 21(2):249-261.

14. MAÏ HA, Demmouche A. A Case- Control study of Body Mass Index and Infertility in Algerian Women (Sidi Bel Abbes, West of Algeria). Int J Infertil Fetal Med . 2015; 6(3):103-107.

15. Caillon, H., Fréour, T., Bach-Ngohou, K., Colombel, A., Denis, M. G., Barrière, P., \& Masson, D. Effects of female increased body mass index on in vitro fertilization cycles outcome. Obesity research \& clinical practice. . 2015; 9(4):382-388.

16. Jain, A., Polotsky, A. J., Rochester, D., Berga, S. L., Loucks, T., Zeitlian, G., \& Santoro, N. Pulsatile luteinizing hormone amplitude and progesterone metabolite excretion are reduced in obese women. The Journal of Clinical Endocrinology \& Metabolism. 2007; 92(7):2468-2473.

17. Navarro, G., Allard, C., Xu, W., \& Mauvais-Jarvis, F. The role of androgens in metabolism, obesity, and diabetes in males and females. Obesity. 2015; 23(4):713-719.

18. Hormones, E., \& Breast Cancer Collaborative Group. Sex hormones and risk of breast cancer in premenopausal women: a collaborative reanalysis of individual participant data from seven prospective studies. The lancet oncology. 2013; 14(10):1009-1019.

19. Schummers L, Hutcheon JA, Bodnar LM, et al. Risk of adverse pregnancy outcomes by prepregnancy body mass index: a populationbased study to inform prepregnancy weight loss counseling. Obstet Gynecol 2015 ; 125:133-43.

20. Marchi J, Berg M, Dencker A, et al. Risks associated with obesity in pregnancy, for the mother and baby: a systematic review of reviews. Obes Rev $2015 ; 16: 621-38$.

21. Sanabria-Martínez G, García-Hermoso A, Poyatos-León R, et al. Effectiveness of physical activity interventions on preventing gestational diabetes mellitus and excessive maternal weight gain: a meta-analysis. BJOG $2015 ; 122: 1167-74$. 